\title{
Los trastornos de la Isla de la Tortuga
}

\author{
Por Juan Duchesne Winter ${ }^{1}$ \\ Centro de Estudios Latinoamericanos, \\ Universidad de Pittsburgh (EE.UU)
}

Hace unos meses José Buscaglia publicó un artículo de apenas veinte páginas que merece más comentarios que muchos mamotretos enjundiosos. Se titula "El Caribe al final de la era usoniana. Hacia un nuevo modelo de confederación", y aparece en el número 23 de la revista Aguaita, del Observatorio del Caribe en Cartagena de Indias. Me propongo resumirlo y "sacarle punta", sumándole algunas ideas. El título va directo al tema. Buscaglia asume el pésimo diagnóstico económico-político de los Estados Unidos, discutido ya como asunto de primer orden por una gran cantidad de analistas fuera y dentro de ese país. La "gran nación" va viniendo a menos y todo indica que terminaron para siempre jamás sus días "gran". ¿Cómo pinta el escenario del Caribe tras este mutis por el foro de la potencia que lo consideró una vez su mare nostrum, cual el imperio romano le llamó al Mediterráneo? Buscaglia responde con un análisis y una propuesta brillante.

Antes que nada, la primera nota del artículo aclara que emplea el neologismo "usoniano" para referirse a Estados Unidos (U.S.A.), porque se reserva el gentilicio americano para un solo continente, América, que abarca Sur, Centro y Norte, más todos los archipiélagos contiguos. Un nombre puede hacer mucho en esta vida. Buscaglia despoja así de toda su mística envolvente al nombre de la "gran nación" para devolverla a su dimensión provinciana. ¡Qué mejor forma de iniciar la descripción de un escenario donde los actores principales pierden sus roles! Los acontecimientos lo solicitan. $\mathrm{Su}$ artículo destaca varios eventos emblemáticos que ilustran el declive usoniano. Un hito del comienzo de la era usoniana, según el autor, podría serlo el régimen militar norteamericano establecido en

\footnotetext{
${ }^{1}$ Investigador puertorriqueño. Presidente del Departamento de Lenguas y Literaturas Hispánicas de la Universidad de Pittsburgh. Director de publicaciones del Instituto Internacional de Literaturas Iberoamericanas (IILI) y de la Revista Iberoamericana de la misma universidad. Autor de Narraciones de testimonio en América Latina (1992), Política de la caricia (1995), Ciudadano insano (2000), Fugas incomunistas (2005), Andrés Caicedo y la utopía del trance (2007), Del príncipe moderno al señor barroco en Paradiso, de José Lezama Lima (2008), Comunismo literario (2009) y La guerrilla narrada (2010), entre otros. e-mail: duchesne@pitt.edu
} 
Puerto Rico en 1898 al concluir la guerra hispanoamericana, y un hito del fin de esa era podría ser el abandono de dicha plaza en un futuro cercano. Pero existe una cantidad de eventos emblemáticos. En 1999 -un siglo después del comienzo de la era usoniana-, se "le otorgó a la compañía Hutchinson Whampoa Limited licencia de operación de los puntos de entrada al Canal de Panamá en Balboa y Colón por cincuenta años. Esta compañía, con sede en Hong Kong, está enteramente en manos de las fuerzas armadas de la República Popular China." (Buscaglia, 2011: 40).

En 2011 se anunció la construcción de una mega-ferrovía entre Buenaventura y Cartagena, capaz de transportar más carga que el Canal de Panamá. La misma estará controlada en función del mercado chino y sus intereses mineros y comerciales en Suramérica y el Caribe. Recordemos cuando Teodoro Roosevelt dijo en 1903: "Tomé Panamá". Pues Panamá ahora es sólo el corredor más visible de la evacuación general del poder yanqui, que incluye a los aliados europeos que cobijaron su injerencia colonial en la región bajo el monopolio estadounidense sobre la misma. Sabemos que la lista de incursiones económicas y financieras chinas en lo que antes era territorio exclusivo de Usonia en América es larga y se extiende. Cada lector puede aportar datos con sólo teclear la red. Pero ¡ojo!, a Buscaglia no le interesa denunciar ningún "peligro amarillo", sino repasar indicaciones dramáticas de la disolución de la Doctrina Monroe entre las cuales, si bien es un actor cada vez más importante, China sólo comparte la escena con otros malandrines poderosos que se disputan grandes cuotas de depredación en el Caribe, como lo son Brasil, los carteles narcos y un Estados Unidos reducido a contendiente imperial de número, sin exclusividad. Buscaglia cita varias señales de la pérdida de influencia, e incluso de pérdida de interés imperial de EEUU en el Caribe y América Latina, desde el fracaso del ALCA ante el Mercosur, hasta el pedido patético del presidente Obama en su visita a Cartagena el 2012 para que, por favor, compren más productos usonianos para aliviar la crisis de su país.

Por otra parte, nuestro autor se desmarca de las retóricas antiimperialistas jurásicas, al no ver en Cuba ni Venezuela alternativas antiimperialistas con impacto propio, sino fichas de Brasil en sus proyecciones de potencia rival de China, Estados Unidos y los Narcos. Lo anterior lo explica haciendo referencias concretas a los poderosos mecanismos de control financiero y económico que el gigante lusófono despliega sobre sus socios "solidarios". Para nada ve Buscaglia gran potencial transformador en el llamado frente bolivariano, al cual él parece concebir como una derivación apenas actualizada (yo diría que muy mejorada en cuanto a la democracia 
racial) del modelo caudillista y autoritario del estado criollo del cual Simón Bolívar precisamente fue emblema. Recordemos que el concepto federativo de Bolívar fue centralizado y moldeado como estado macro-nacional fusionado y calcado del proyecto estadounidense de unir segmentos coloniales en un estado central concebido como nación.

Buscaglia repasa someramente, pero con datos impresionantes, la inviabilidad crónica de los estados nacionales del Gran Caribe, es decir de Caribe real, que incluye no sólo las islas, sino todas las regiones continentales con litoral caribeño. Uno tras otro prueban ser estados perforados como colador por la corrupción y la violencia. Jamaica, Honduras, Guatemala, República Dominicana, Puerto Rico (estado colonial-nacional) y otros están absorbidos por el narcopoder. Cuba de ningún modo queda excluida en este análisis de la espiral de violencia y corrupción estatal y social. El lenguaje de Buscaglia presenta a los narcos como una potencia adicional, en pugna con las otras potencias depredadoras que se ciernen sobre el Caribe, cual China, Brasil y EEUU. Habría que ver, sin embargo, la cuantiosa información que apunta a que la narcoeconomía y la narcopolítica no son fuerzas rivales extrañas a los estados nacionales caribeños, y mucho menos a las potencias dominantes, por lo menos en el caso de EEUU, sino parte consustancial de su funcionamiento contemporáneo.

De ahí que el término "narcoestado" no sea una metáfora, más bien es expresión literal de lo que ocurre en Jamaica, Puerto Rico, México, zonas de Estados Unidos y otras jurisdicciones. Ello, por supuesto, refuerza el diagnóstico de Buscaglia de la incapacidad total de los estados del Gran Caribe para presentar una alternativa al nuevo escenario de dominio imperial múltiple, en manos de China, Brasil, el narcopoder y un Estados Unidos que abandona su rol de policía regional para reconfigurarse como miembro de número de un nuevo club imperial más repartido ${ }^{2}$. Buscaglia, en fin, descarta toda opción política articulada en torno al poder estatal-nacional y su soberanía.

Nuestro autor recurre, entonces, a lo que Walter Benjamin llamó las "tradiciones interrumpidas" de los pueblos y nos presenta la tradición de la ciudad-estado caribeña constituida por Cartagena de Indias. Cartagena se declaró república independiente en 1811, pero no se erigió como nación o imperio, sino como ciudad estado con aspiraciones sociales y políticas igualitarias y antirracistas

${ }^{2}$ Esto, en una situación en la cual apenas se puede distinguir entre la DEA y los narcos. Leer en el libro de Winslow (2010) cómo la DEA creó los carteles mexicanos. 
que desafiaron las aspiraciones de las élites criollas caraqueñas y del altiplano andino. Su sistema de gobierno fue ciudadano antes que caudillista o militarista. Ello condujo a que Bolívar atacara a Cartagena por considerar la existencia de una ciudad estado de ese tipo una anomalía intolerable para su modelo caudillista, autoritario y racialmente jerarquizado de la nación.

El bolivarianismo decimonónico mostró de este modo cómo supeditaba sus aspiraciones anticoloniales e independentistas a la preservación de un colonialismo interno de dominio racial y social de las élites criollas sobre los sectores subalternizados bajo su dominio nacional. Buscaglia traza con admirable consistencia crítica las redes históricas inter-caribeñas que vinculan el acontecimiento cartagenero, la resistencia confederacionista-antillanista de Ramón Emeterio Betances en varias coyunturas y escenarios del Caribe, las ideas anti-caudillistas de los revolucionarios haitianos Toussaint L'Overture y Alexandre Pétion, y el igualitarismo racial de un Antonio Maceo, marginado por la élite independentista cubana y muerto sospechosamente durante la guerra de independencia en esa isla.

A partir de esta red o rizoma de acontecimientos, José Buscaglia arma una política posible para el presente y el futuro del Gran Caribe, cuyo emblema de soberanía ya no es la nación, sino la confederación. El autor argumenta que, dada la inviabilidad de los estados nacionales caribeños y la raigambre caudillista autoritaria de las tradiciones basadas en la "liberación nacional" (entre las que incluye el bolivarianismo actual, cual la política de Hugo Chávez en Venezuela y la dinastía de los hermanos Castro en Cuba), la presente coyuntura de reflujo del poder imperial exclusivo de Estados Unidos ofrece una oportunidad para impulsar la idea de raíz cartagenera y betancina de las ciudades estado y su confederación como bases ciudadanas de soberanía popular frente a los nuevos imperialismos emergentes tras el ocaso de lo que en idioma usoniano se llamó el American Century.

El artículo se convierte en un verdadero manifiesto cuando propone, en su última parte, "la creación de un Congreso de Ciudades Caribeñas o CCC" (54), fundado sobre principios de respeto a los fueros locales, la autogestión, el igualitarismo social y racial, asambleas ciudadanas, gobiernos civiles colectivos y temporeros sin reelección, sin caudillos ni jefes militares, y sostenibilidad ecológica. Esta propuesta convierte el texto en una convocatoria, cuanto más que propone unos lineamientos concretos para realizar el ideal del CCC, con el convencimiento de que otra era más de fragmentación y explotación sólo la puede evitar una red de ciudades libres extendida 
desde Kingston a Colón, a Cartagena, a San Juan; o para citar al autor: "desde Bridgetown a La Habana, de San Andrés a Freeport [...] desde Cumaná a Chetumal que envíen delegados a las primeras reuniones del CCC" (56) y comiencen a tomar en sus manos la ejecución de proyectos de desarrollo de las economías locales y las formas de vida urbana, potenciados por la redes de influencias inter-caribeñas e internacionales que les provee su sistema confederado. Este modelo suplantaría a los estados nacionales (y coloniales), al parecer, gradualmente y sin recurrir a la violencia (al menos la de tipo militar), según implica el lenguaje empleado por Buscaglia, pues la unidad básica sería cada ciudad que se incorporara voluntariamente al CCC, junto a su zona de influencia inmediata o "hinterland". Buscaglia llega al punto de diseñar una bandera del Congreso de Ciudades Caribeñas basada en la enseña de la República de Cartagena de Indias de 1811.

Algún lector podrá decir que el autor de este artículo-manifiesto se ha ido en un vuelo utópico. Ese lector se preguntará - ¿qué se ha fumado este tipo?-, pero no necesariamente estamos aquí ante una propuesta utópica basada en el sentido de no-hay-tal-lugar o en las abstracciones típicas del utopismo europeo. No se propone un modelo universal higiénicamente depurado para resolver por la eternidad los problemas de toda sociedad humana, sino una manera de continuar la política de otra forma, adoptando horizontes diferentes, abiertos por tradiciones interrumpidas de la experiencia popular, ante un cambio del escenario geopolítico de gran envergadura, como es el fin de la hegemonía exclusiva de los Estados Unidos después de más de un siglo de control y expolio en colaboración con las élites nacionales y las otras potencias europeas afincadas en la zona. Se suma el agravante de que ese final usoniano no trae el fin del colonialismo, sino nuevas entidades de corte nacional-imperial que se disputan los espacios de dominio dejados vacantes en medio de las ruinas de los estados nacionales realmente existentes. La propuesta de Buscaglia consiste en aprovechar tal coyuntura para concebir políticas de largo alcance sobre bases diferentes, más allá del modelo inviable, al menos para el Caribe, del estado nacional; y al hacerlo se basa en prácticas recuperadas por la memoria histórica colectiva de la región, no en una abstracción especulativa.

Lo importante, aparte de la seria consideración literal que merece esta propuesta, es que convoca a situarse mental y físicamente en otro horizonte, en otro espacio de posibilidades, en un espacio material compuesto de sistemas geológicos, geográficos y climáticos, constelado de flujos, cuerpos, ecologías y poblaciones, con sus lenguajes, discursos y relaciones que llamamos Caribe. Al proponer una red de ciudades libres y confederadas que asuman el territorio 
concreto donde radican como plano de consistencia para una política alternativa, Buscaglia desafía la colonialidad abstracta, ideológica, envenenada de prejuicios, racismos, dependencias, autodesprecios, culpas y deudas impagables que ha segmentado al Caribe en función de los intereses de las potencias imperiales de turno. En lugar de vivir como el archipiélago que es, en cuanto espacio de relaciones entre costas, ríos, deltas, mares, selvas, planicies, montañas, médanos, humedales, islas y continentes, el Caribe contemporáneo malvive en el insularismo, en islas que funcionan como fortalezas, arsenales, prisiones, guetos, enclaves, laboratorios y resorts, según las necesidades de las potencias que se lo reparten continuamente. Estamos en la era de las redes electrónicas, pero en Kingston no se tiene idea de lo que ocurre en San Juan ni viceversa. Cada ínsula vive enchufada en directo al consumo y expolio de una metrópoli distante y ajena, en ignorancia y apartamiento del mundo inmediato que la constituye como vida.

Pero no siempre ha sido así. Las sociedades amerindias del Caribe supieron vivir, sin contar con i-pads ni celulares, en un espacio autogestionado, enriquecido por vínculos cercanos y distantes. Se calcula que cualquier mensaje u objeto de intercambio podía llegar en cinco días a cualquier punto del Gran Caribe, incluyendo los interiores continentales del delta del Magdalena, la Orinoquia y zonas de Mesoamérica conectadas por vías fluviales. Los pueblos de lengua Caribe que dan nombre a la región se movían en sus piraguas por las redes fluviales y marítimas de la región, desde las costas de Yucatán a las remotas selvas del Orinoco y el Amazonas, con una eficacia que pondría en evidencia la mediocridad de las compañías actuales de transporte. El arqueólogo puertorriqueño Reniel Rodríguez Matos ha realizado estudios que demuestran la existencia de una red de relaciones intensas y continuas entre los pueblos amerindios del Caribe y sus congéneres de Mesoamérica, los Andes, la Amazonía, la Orinoquia y las tierras del Bío Bío que niegan la fe casi metafísica de la academia moderna en un Caribe estrictamente insular y separado de América Latina. Para citar una evidencia entre cientos, Reniel Rodríguez ubica en un yacimiento de la isla de Puerto Rico de miles de años de antigüedad un sofisticado y elaborado artefacto ritual, casi idéntico al que hoy día utilizan los pueblos amerindios de la Sierra Nevada de Santa Marta.

Reniel Rodríguez se pregunta de dónde viene la concepción absurda de que el Caribe siempre estuvo encerrado en un espacio insular ajeno a las zonas continentales con las cuales tiene nexos tan densos e intensos. Sitúa, entonces, al menos un foco institucional de esa ideología en la gestión del Puerto Rico Survey hacia 1914, dirigido 
por antropólogos destacadísimos como Franz Boas, Jesse W. Fewkes e Irving Rouse. Reniel Rodríguez vincula los documentos y postulados de esta gestión a la geopolítica de Estados Unidos y de las potencias europeas (Francia, Inglaterra, Holanda) que se han cobijado bajo el dominio estadounidense para mantener su injerencia en la región durante el siglo XX. Como deja ver Antonio Gaztambide (2006) en otro estudio donde también favorece un concepto continental del Caribe, es bastante obvio el ánimo geopolítico de la fragmentación insularista promovida por Estados Unidos tras su toma de posesión de la zona en el 1898.

Añado este excurso por el espacio amerindio caribeño porque, a mi juicio, contribuye a articular a mayor escala el espacio de posibilidades convocado por el planteamiento de Buscaglia. Las investigaciones de Reniel Rodríguez sobre las tradiciones interrumpidas amerindias lo llevan a postular un Gran Caribe reticular, constituido de redes, más que de áreas. Yo añadiría que esa retícula puede concebirse como un rizoma, en el sentido, no sólo de no depender de ningún centro, tronco o raíz dominante, sino que prevalecen las relaciones mismas sobre los puntos o nódulos que se relacionan, un poco a la manera sugerida en la Poética de la relación (1990), del martiniqueño Édouard Glissant. Además, es importante constatar que el rizoma o retícula articula un espacio material concreto, pero no fija un área delimitada o cuantificada por bordes ni perímetros, permitiendo una basculación flexible, sutil, reversible, entre lo interior y lo exterior. La espacialidad amerindia del Caribe, dado su manejo paradójico de la inmanencia y la exterioridad, potencia esa materialidad rizomática.

Los indios caribeños no son un expediente cerrado por el exterminio ni asunto exclusivo de yacimientos arqueológicos. Esa creencia es parte de la ideología insularista que precisamente criticamos y también es artículo de fe del mestizaje compulsivo impuesto por los proyectos nacionales e imperiales. Existen comunidades indígenas a lo largo y ancho del Gran Caribe que no sólo testimonian su resistencia, sino que producen un espacio de posibilidades alternativo: basta mencionar a los gnöbe de Panamá, los kuna de Panamá y Colombia, los miskitos de Nicaragua, los garífuna de Belice y Guatemala, los wayuu de la Guajira colombo-venezolana, los kogi, wiwa y aruacos de la Sierra Nevada de Santa Marta, los yukpa, bari, añú de la Sierra del Perijá y el Golfo de Maracaibo, los caribe de Dominica y tantos otros hablantes de la familia de lenguas caribe, tupi-guaraní, arawak y otras de la Orinoquia. Ante la compulsión estatal del mestizaje, estos pueblos presentan una práctica de la diferencia que mucho puede contribuir al rizoma caribeño y sus políticas posibles. Pretendo sumar, entonces, una ampliación amerindia al brillante espacio de posibilidades 
desplegado por el análisis de José Buscaglia ante el fin de la era usoniana. Cabe apuntar que en la escala temporal y espacial ampliada implícita en esta suma, la entidad política "usoniana" designada por Buscaglia es sólo un episodio más de los trastornos de la Isla de la Tortuga, según los amerindios llaman desde hace cientos de siglos a Norteamérica.

\section{Bibliografía}

Buscaglia, J. (2011). "El Caribe al final de la era usoniana. Hacia un nuevo modelo de confederación", Aguaita, Revista del Observatorio del Caribe Colombiano, $\mathrm{n}^{\circ}$ 23, Cartagena, pp. 38-58.

Gaztambide, A. (2006). Tan lejos de Dios... Ensayos sobre las relaciones del Caribe con Estados Unidos. Puerto Rico: Ediciones Callejón.

Glissant, E. (1997). Poetics of relations. Ann Arbor: University of Michigan.

Winslow, D. (2010). El poder del perro. Barcelona: Random House Mondadori. 